\title{
Analyse des contraintes foncières et culturales du maraichage dans le département de Kantché au Niger: cas du périmètre irrigué de Tassaou
}

\author{
Illou Mahamadou \\ Université de Zinder, Département de géographie \\ Bonkoungou Joachim \\ Ouagadougou, INERA, Burkina Faso \\ Souley Kabirou \\ Université de Zinder, Département de géographie \\ Oumarou Bagoudou Sani \\ Etudiant Master II, département géographie, Université de Zinder
}

Doi: 10.19044/esj.2018.v14n30p240 URL:http://dx.doi.org/10.19044/esj.2018.v14n30p240

\begin{abstract}
Irrigated crops are a credible alternative when it comes to freeing agricultural production from rainfall hazards. In addition to the irregularity and poor distribution of rainfall, the department of Kantché suffers from enormous problems related to the environment, socio-economic and sociodemographic contexts. This work proposes to analyse land and cultural constraints in order to promote the local economy. The objective is to diagnose the question of distribution and access to land. It is also a critical examination of the evolution of crops and the main constraints. To achieve this objective, the methodological approach was based on socio-economic surveys that collected quantitative and qualitative data. The main results show that there are disparities in land availability among farmers. Inheritance remains the main mode of access to land, but the purchase is becoming more and more important. With regard to crops, environmental and socio-economic conditions have led producers to abandon some crops in favor of others. The major difficulties are the poor distribution and irregularity of rains, the drop in soil fertility, parasitic attacks and cultivation techniques.
\end{abstract}

Keywords: Land, irrigation, types of crops, constraints, Kantché, Tasaou, Niger

\section{Résumé}

Les cultures irriguées constituent une alternative crédible lorsqu'il s'agit de libérer la production agricole des aléas pluviométriques. Outre 
l'irrégularité et la mauvaise répartition des précipitations, le département de Kantché souffre d'énormes problèmes liés à l'environnement, aux contextes socioéconomiques et démographiques. Ce travail propose d'analyser les contraintes foncières et culturales dans le but de promouvoir l'économie locale. L'objectif consiste à diagnostiquer la question de répartition et de mode d'accès à la terre. Il s'agit de faire un examen critique sur l'évolution des cultures et les principales contraintes. Pour atteindre cet objectif, la démarche méthodologique s'est appuyée sur des enquêtes socioéconomiques. Les principaux résultats montrent qu'il existe des disparités dans la disponibilité foncière entre les paysans. L'héritage reste le principal mode d'accès à la terre, mais l'achat prend de plus en plus d'ampleur. S'agissant des cultures, les conditions environnementales et socioéconomiques ont amené les producteurs à abandonner certaines cultures au profit d'autres économiquement plus rentables. Les contraintesmajeures des producteurs sont la mauvaise répartition et l'irrégularité des pluies, la baisse de fertilité des sols, les attaques parasitaires et les techniques culturales traditionnelles.

Mots clés: Foncier, irrigation, types de cultures, contraintes, Kantché, Tasaou, Niger

\section{Introduction}

Le Niger est un pays sahélien enclavé avec une superficie de 1267000 $\mathrm{Km}^{2} . \mathrm{Il}$ est compris entre $0^{\circ} 16^{\prime}$ et $16^{\circ}$ de longitude Est et $11^{\circ} 1^{\prime}$ et $23^{\circ} 17^{\prime}$ de latitude Nord. Les $3 / 4$ du pays sont occupés par le désert notamment celui du Ténéré.Sa population est estimée à 17129076 habitants, avec un taux de croissance de 3,9\% par an. Cette population est rurale à $79 \%(\mathrm{RGP} / \mathrm{H}$, 2012).Le principal moyen de subsistance des ruraux est l'agriculture, une activité qui fait face à plusieurs contraintes, particulièrement la forte pression démographique sur les ressources naturelles et l'irrégularité et la mauvaise repartions spatio-temporelle des précipitations.

Le département de Kantché est situé dans la partie ouest de la région de Zinder. Il couvre une superficie de $2381 \mathrm{Km}^{2}$ qui s'étend en longitude entre $8^{\circ} 49^{\prime}$ et $8^{\circ} 45^{\prime}$ Est, et en latitude entre $13^{\circ} 19^{\prime}$ et $13^{\circ} 49^{\prime}$ Nord.

Matamèye, chef-lieu du département est situé à $87 \mathrm{Km}$ de Zinder cheflieu de la région et à $850 \mathrm{Km}$ de Niamey, capitale du Niger. Le département est limité au nord et à l'est par le département de Mirriah, à l'ouest par le département de Tessaoua et au sud par le département de Magaria et la République fédérale du Nigeria avec laquelle il partage une frontière d'environ $10 \mathrm{Km}$.

Le site de Tassaou est situé au nord-est de Matamèye, dans la commune de Kantché qui porte le nom du chef-lieu du département. Il couvre une superficie de 44,8 hectares. Le sol est argilo-sableux, propice pour les 
cultures maraichères. Le village présente les mêmes caractéristiques que Kantché qui couvre une superficie de $281 \mathrm{Km}^{2}$ avec une population estimée à 399181 habitants. La majorité de cette population est jeune $(64,37 \%$ ont moins de 20 ans et 83,11\% ont moins de 35 ans), selon le RGP/H de 2012. C'est l'un des départements les plus densément peuplés du Niger avec 168 habitants au $\mathrm{Km}^{2}(\mathrm{RGPH}, 2012)$. Cette population est repartie dans neuf communes rurales (figure 1) et compte 273 villages administratifs, 66 tribus, plusieurs hameaux et campements (PDC, 2014).

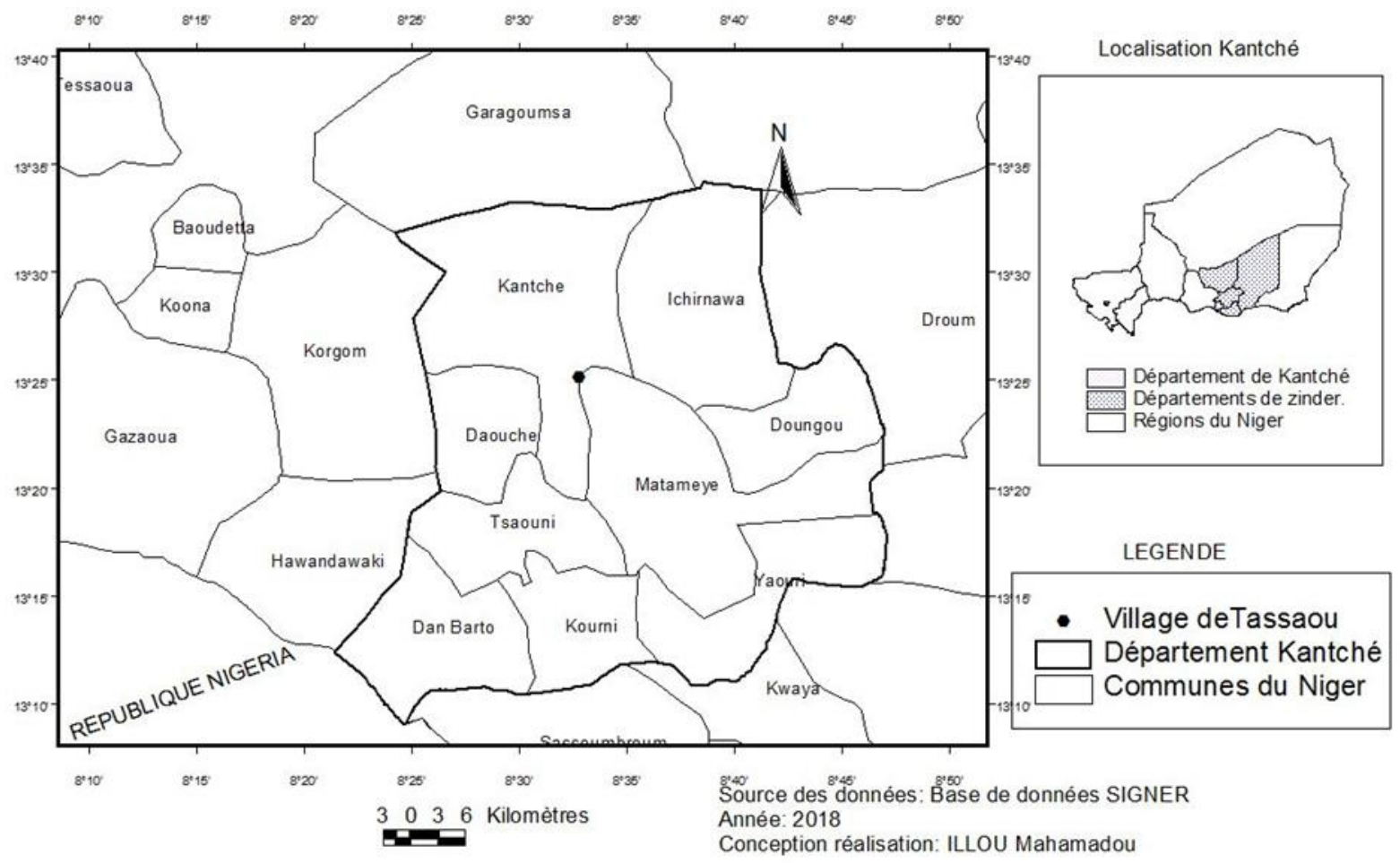

Figure 1: Localisation de la zone d'étude

Les Haoussas sont majoritaires et cohabitent avec des Peulhs et des Touaregs. Ces principaux groupes ethnolinguistiques sont très vulnérables. Selon les résultats de l'enquête Nationale sur la vulnérabilité à l'insécurité alimentaire au Niger de novembre 2013 réalisée par le Système d'Alerte Précoce (SAP), 42,7\% de la population du département de Kantché est en insécurité alimentaire sévère et modérée. Les activités agricoles connaissent des problèmes liés aux aléas climatiques et à la pression démographique. Les terres agricoles sont soit morcelées soit insuffisantes pour supporter la forte croissance démographique. 
Le sol du site de Tassaou est argilo-sableux, propice pour les cultures maraichères (légumes et arbres fruitiers). La source d'eau est souterraine.

Le présent travail qui vise à analyser la gestion du périmètre irrigué de Tassaou présente la problématique, expose par la suite les objectifs de la recherche et la méthodologie. Enfin, les résultats sont structurés de manière à répondre à la question de recherche posée.

\section{Problématique}

Le Niger est situé au cœur de l'Afrique occidentale où les températures et les précipitations sont inégalement réparties et varient selon les régions. Cependant quatre zones agro-climatiques se distinguent selon les aspects physiques, démographiques et socio-économiques. Il s'agit de la zone saharienne, définie par une pluviométrie moyenne annuelle inférieure à 200mm; la zone saharo-sahélienne,une transition entre le Sahara et le Sahel,àpluviométrie moyenne annuelle comprise entre 200 et 300 millimètres permettant le développement de l'agriculture pluviale notamment le mil ;la zone sahélienne, définie par une pluviométrie moyenne annuelle comprise entre 300 et 400 millimètres où l'agriculture est pratiquée, surtout les céréales pures ou en association avec les légumineuses et la zone soudanienne de pluviométrie moyenne annuelle supérieure à 600 millimètres, qui ne représente que $1 \%$ de la superficie du pays.

Le Niger est un pays d'Afrique subsaharienne dont l'économie repose sur l'agriculture et l'élevage. Cette dernière contribue à hauteur de $40 \% \mathrm{du}$ PIB nationale (SDR, 2003). Elle mobilise à elle seule $91 \%$ de la population. Malgré sa situation désertique, l'agriculture constitue l'un des piliers de l'économie nigérienne. Ainsi pour assurer la sécurité alimentaire les populations développent des cultures maraichères ou des cultures de contre saison (Benoit, 2016 ; Apollin, 2016 ; Leyronas, 2016).

A la fin des cultures pluviales, le maraichage devient une source de revenu pour beaucoup de jeunes nigériens et est une alternative à leur exode.

Dans un contexte de pauvreté généralisée, de crise de migration et son corolaire de désastre vers le Maghreb et l'Occident, les populations rurales du département de Kantché développent des stratégies pour faire face au déficit pluviométrique. C'est ainsi que les cultures irriguées se développent de plus en plus dans la région avec l'appui de l'Etat et des ONG. Outre ce contexte de pauvreté généralisée et de crise migratoire, les contraintes d'ordre démographique pèsent sur l'équilibre des ménages. En conséquence, le secteur agricole fait face à une pression de la population sans cesse croissante. Les interventions de l'Etat et de ses partenaires, aident les maraîchers à renforcer leur activité dans le but d'accroitre les rendements et de contribuer au développement rural et à une meilleure préservation des ressources naturelles notamment l'eau. Le maraîchage est une activité qui offre beaucoup 
d'opportunité en termes de diversification des activités et limite l'exode rural par la création des conditions de vie plus favorables dans les campagnes. Pour une meilleure valorisation de cette activité, les populations de la zone fixent des lois et règlement de bonnes pratiques.

Dans ce milieu, ou tout est défis, le problème principal consiste à se demander, quelles sont les contraintes du maraichage dans le département de Kantché ?

Trois problèmes spécifiques qui constituent le problème principal, se posent, à savoir :

Quelles sont les contraintes liées au foncier?

Quelles sont les types de cultures et leurs évolutions?

Quelles sont les contraintes de production?

\section{Objectifs de l'étude \\ Objectif général}

L'objectif général de l'étude consiste à analyser le système d'exploitation du périmètre irrigué de Tassaou à travers l'examen de l'accès à la terre et a l'évolution des pratiques culturales sur le site.

\section{Objectifs spécifiques}

Pour atteindre l'objectif général de cette étude, les objectifs spécifiques ci-après doivent être atteints :

- analyser la question foncière. La terre étant considéré comme le premier capital de production, il convient d'étudier les disparités dans l'accès au foncier afin de proposer des mesures visant une mise en valeur optimale de cette ressource ;

- analyser les pratiques culturales et leurs évolutions ;

- examiner les contraintes de production en abordant les conditions pluviométriques, l'usage des pesticides et leur impact sur la fertilité des sols, les attaques parasitaires et les techniques de culture.

\section{Les hypothèses}

Pour atteindre les objectifs assignés à l'étude, les hypothèses ci-dessus sont formulées :

- L'accès à la terre fait l'objet de grandes disparités entre les paysans, dû essentiellement à la pauvreté en milieu rural.

- Les conditions physiques et socioéconomiques ont occasionné l'abandon et la réintroduction de plusieurs types de cultures considérés comme une adaptation aux nouvelles conditions de l'environnement et des marchés.

- Les contraintes de productions sont multiples et variées dans la zone d'étude. 


\section{Méthodologie}

La démarche méthodologique qui a conduit à la réalisation de cette étude, repose sur la revue de littérature, la justification du choix du site, l'élaboration d'un questionnaire et d'un guide d'entretien, l'échantillonnage et les enquêtes. Après ces phases, interviennent les phases de dépouillements et rédaction.

\section{La revue de littérature}

Avant de poser la problématique, il est nécessaire de commencer le sujet à travers une recherche bibliographique. Cette dernière a permis de bien se positionner par rapport aux études antérieures concernant la question.

\section{Le choix du site}

Le département de Kantché se caractérise par un contexte socioéconomique répulsif. En dehors de l'agriculture pluviale, les opportunités d'emplois sont très limitées et peu attrayantes. Outre l'émiettement des terres de cultures, les populations utilisent toujours des techniques culturales traditionnelles avec de faibles rendements. A cela s'ajoute une pression démographique la plus importante du pays avec 168 $\mathrm{hbts} / \mathrm{km}^{2}$ (RGP/H, 2012). Ce département connait une insuffisance des études scientifiques notamment sur les maraichages. Tels sont les raisons qui ont motivées le choix du site de Tassaou.

\section{L’échantillonnage}

L'échantillonnage a été fait de manière aléatoire. 79 (sur environ 200 selon les populations) paysans devant rendre compte de la situation de leurs ménages ont été sélectionnés. Dans cet échantillon, une catégorisation par activité a été faite pour déterminer ceux qui font le maraichage comme activité principale et ceux qui le pratique à titre d'activité secondaire (tableaul et 2).

Tableau 1: Répartition des paysans en fonction de l'activité principale

\begin{tabular}{|l|l|l|}
\hline Activité principale & Nombre d'exploitants & Pourcentage \\
\hline Culture pluviale & 74 & 93,70 \\
\hline Maraichage & 4 & 5,10 \\
\hline Commerce & 1 & 1,30 \\
\hline Elevage & 0 & 0,00 \\
\hline Total d'exploitants & 79 & 100 \\
\hline
\end{tabular}

Tableau 2 : Répartition des exploitants par activités secondaire

\begin{tabular}{|l|l|l|}
\hline Activité secondaire & Nombre d'exploitants & Pourcentage \\
\hline Maraichage & 34 & 43,00 \\
\hline Elevage & 24 & 30,40 \\
\hline Commerce & 15 & 19,00 \\
\hline Culture pluviale & 4 & 5,10 \\
\hline autres & 2 & 2,6 \\
\hline Total d'exploitants & 79 & 100 \\
\hline
\end{tabular}




\section{La collecte des données}

Les données sont collectées à travers deux types d'entretien. Les entretiens individuels et les focus-group. Les entretiens individuels ont directement consisté à collecter les informations auprès des paysans d'une part. Chaque individu a rendu compte de la situation de son ménage. D'autres parts, ce type d'entretien a permis d'avoir des informations auprès des responsables des services techniques déconcentrés de l'Etat, des responsables coutumiers et administratifs de la commune de Kantché. Les entretiens groupés ont consisté en deux assemblées villageoises. La première a servi de cadre pour expliquer les enjeux de l'étude et la réalisation de l'échantillon. La deuxième a permis la validation des résultats.

Les données collectées sont quantitatives et qualitatives. Elles ont été par la suite dépouillées et analysées à l'aide d'outils de traitement de données (tableur Excel).

\section{Résultats}

\section{Les aspects fonciers}

La terre en milieu rural est considérée comme le premier capital de production. Sa disponibilité détermine, en dehors de son côté prestigieux, le niveau de richesse d'un individu. Sur le périmètre irrigué de Tassaou, les parcelles sont sensiblement de même taille (comprise entre 0,5 et 1 ha). Les disparités sont visiblesdans le nombre de parcelles que possède le paysan. L'accès au foncier constitue également un paramètre de différenciation. Dans cette catégorisation, il importe de distinguer la situation des hommes et des femmes.

\section{La répartition des superficies cultivables}

Le nombre de parcelles que détient un producteur est une variable importante dans l'appréciation des indicateurs de pauvreté en milieu rural. Il faut faire la différence entre le nombre de parcelles détenues et les superficies effectivement mises en valeur. Le poids démographique des ménages et la pauvreté ambiante font qu'à Tassaou, il est très difficile de voir une parcelle non exploitée lorsque l'accès à l'eau est garanti. La figure ci-dessous présente la situation des parcelles détenues.

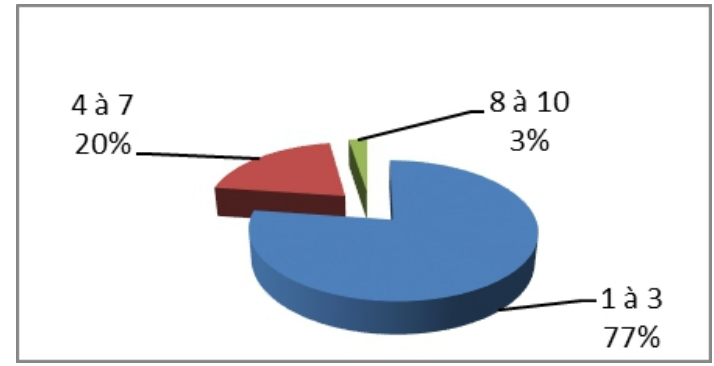

Figure 2: Nombre de parcelles par classe d'exploitant du site de Tassaou 
La figure 2, montre que la majorité des producteurs (77\%) possède 1 à 3 parcelles. $20 \%$ ont entre 4 et 7 et $3 \%$ de maraichers ont 8 à 10 parcelles. Ces résultats traduisent les disparités qui existent dans cette communauté. Une minorité $(3 \%)$ possède 8 à 10 parcellesd'exploitation. Cette situation qui exprime le degré de richesse des ménages, traduit aussi leurs poids démographiques (tableau 3). En tenant compte de ce poids, il convient de relativiser la richesse de ces ménages.

Tableau 3 : Nombre de personnes à charge dans les ménages

\begin{tabular}{|l|l|l|}
\hline Nombre de personnes à charge & Exploitants & Fréquence \\
\hline $1-5$ & 13 & 16,5 \\
\hline $6-10$ & 35 & 44,3 \\
\hline $11-20$ & 22 & 27,8 \\
\hline $21-30$ & 5 & 6,3 \\
\hline $31-40$ & 1 & 1,3 \\
\hline $41-50$ & 2 & 2,5 \\
\hline 0 & 1 & 1,3 \\
\hline Total & 79 & 100 \\
\hline
\end{tabular}

Source : Enquête terrain, 2015

\section{Le mode d'accès à la terre}

Il existe plusieurs modes d'accès à la terre sur le périmètre irrigué de Tassaou (figure 4).

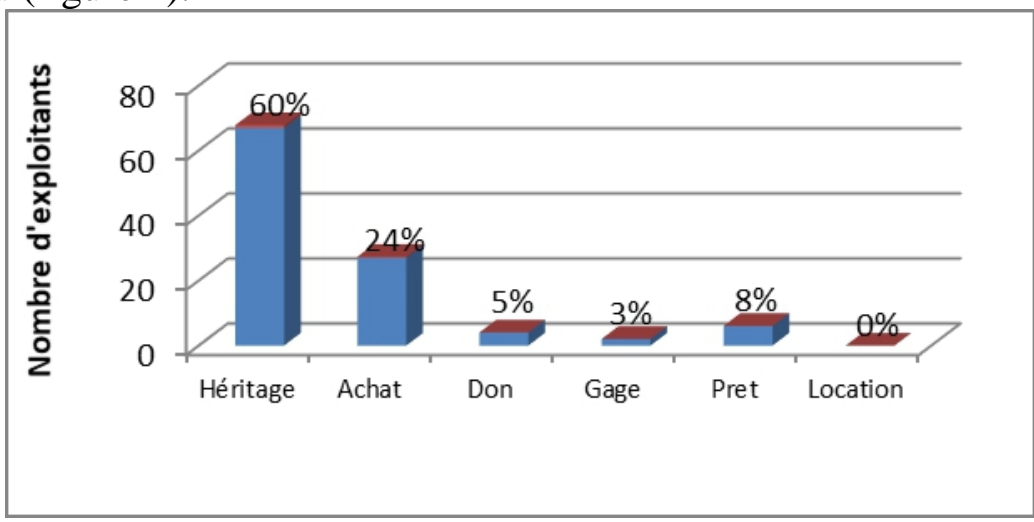

Figure 4 : Mode d'accès aux parcelles

Les principaux modes d'accès à la terre à Tassaou se résument en droit de disposer (l'héritage, l'achat) et en droit d'usage (le don, la mise en gage, le prêt et la location). La figure 4 montre que l'héritage est le principal mode d'accès à la terre. $60 \%$ des paysans ont reçu la terre après partage lors du décès de leurs parents. La nucléarisation des ménages (Yamba, 2014 et2016; PPILDA, 2014), l'émiettement des superficies, la croissance de la population, 
l'individualisation des rapports (Yamba, 2002 et 2004), font que la terre a de plus en plus une valeur marchande, c'est ce qui explique ce taux de $24 \%$ d'accès à la terre par achat. Le don qui est en nette régression constitue avec le prêt et la mise en gage, les autres formes mineures d'accès au foncier.

\section{L'accès des femmes au foncier sur le site}

Les femmes de Tassaou ont plusieurs voix d'accès à la terre sur le périmètre irrigué. La première appropriation a eu lieu grâce à l'intervention du chef de canton de Kantché qui a octroyé au groupement féminin de Tassaou un terrain d'une superficie de 1,6 ha. Cette contribution a boosté l'implication des femmes dans les cultures maraichères comme moyen de lutte contre la pauvreté et l'immigration. L'intérêt suscité a occasionné d'autres formes d'accès (figure 5).

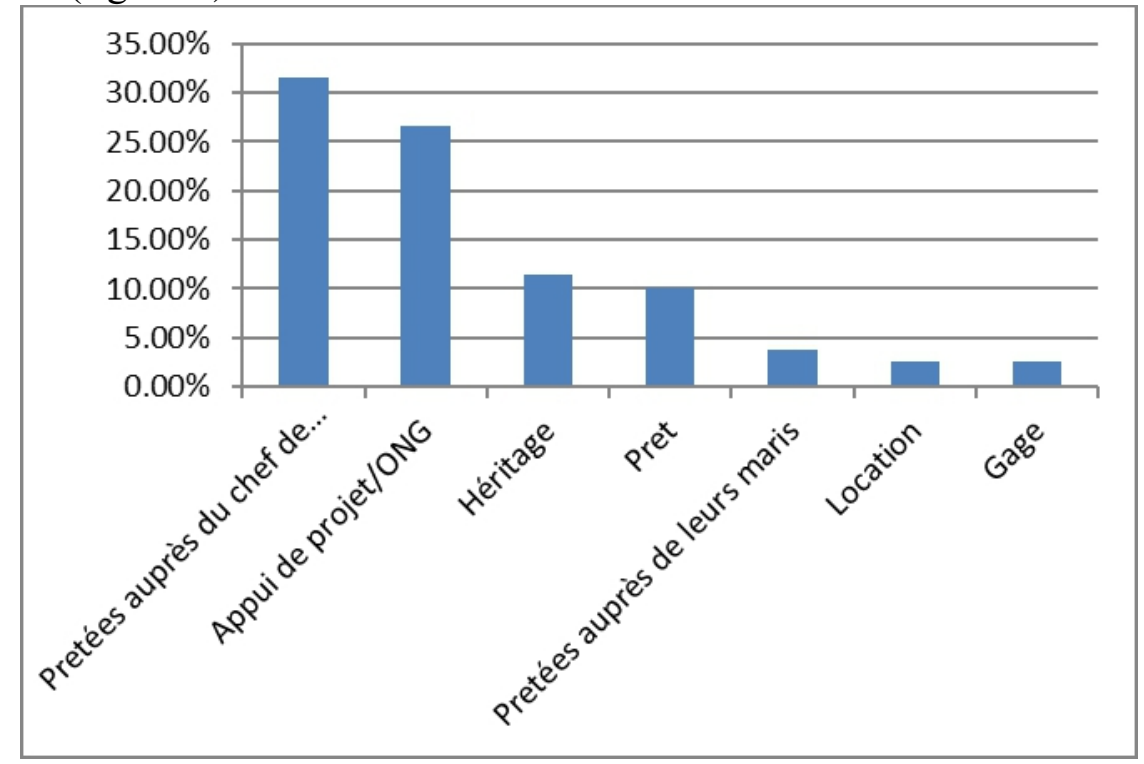

Figure 5: Mode d'accès des femmes aux parcelles

La figure 5 montre que les ONGs et projets œuvrant pour la promotion de la femme en milieu rural s'investissent dans le maraichage en assurant un accès des femmes aux parcelles sur le site. Les autres formes d'accès sont essentiellement l'héritage (13\%) et les prêts.

\section{Les pratiques culturales}

L'examen des pratiques culturales sur le site s'appuie sur la présentation des types de cultures, l'évolution des cultures et les contraintes de production. 


\section{Les types de culture}

Le périmètre irrigué de Tassaou est un exemple de l'évolution du maraichage dans l'ensemble du département de Kantché. Les types de culture sont fonction du contexte économique, environnemental et des possibilités d'écoulement rapide des productions. En effet, le manque d'un système de transformation de récoltes couplé à la faiblesse du tissu des voies de communication oblige les paysans à produire des cultures facilement consommables dans les différents marchés car le risque de péremption est permanent. En tenant compte de ces informations, la figure 6 présente la fréquence des principales cultures.

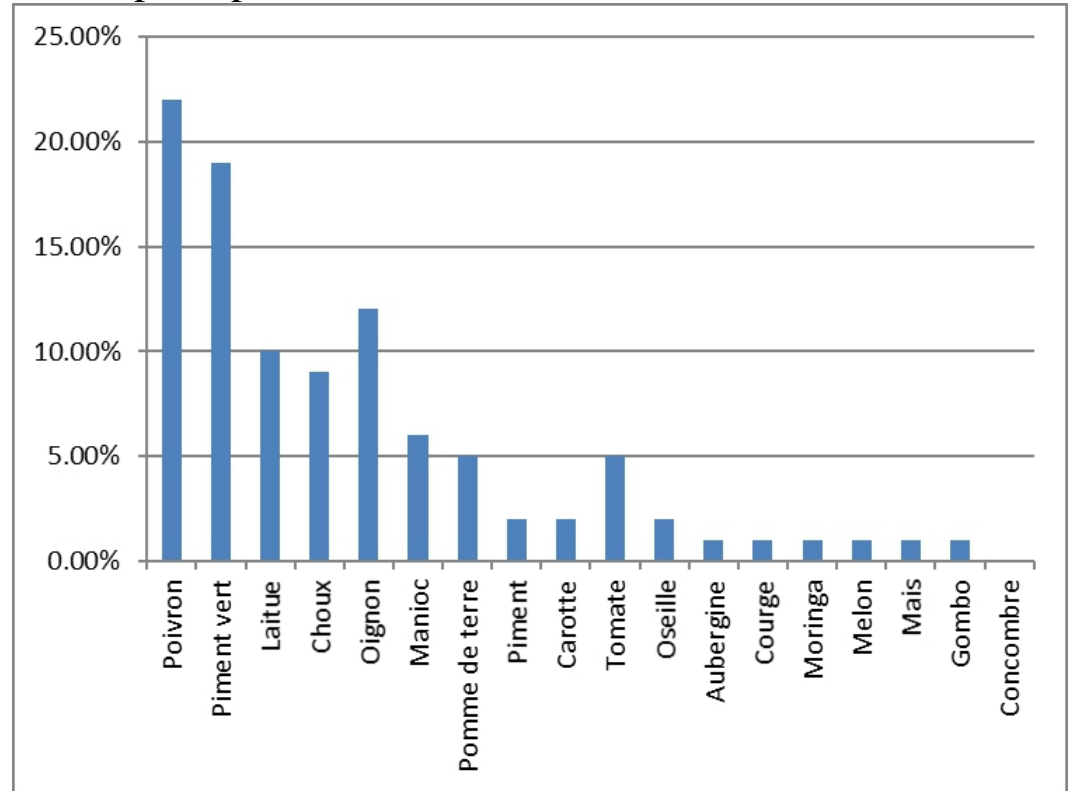

Figure 6: Principales cultures sur le périmètre

La figure 6, montre que le poivron, le piment vert et la laitue sont les principales cultures sur le site. Ces spéculations sont choisies pour leur valeur économique élevée. Le poivron et le piment vert n'ont aucun risque de péremption et peuvent se vendre avec leurs valeurs, frais ou secs. Ce sont aussi des produits très demandés sur les marchés de Zinder, Maradi, Agadez et dans les marchés voisins du Nigéria. Selon les paysans, les plus grands producteurs enregistrent, lorsque la récolte est bonne, des chiffres d'affaires annuels de trois millions de FCFA. Les autres cultures non négligeables sont l'oignon, le chou, le manioc, la pomme de terre. Toutes ces cultures sont à $99 \%$ destinées à la commercialisation. $1 \%$ seulement est utilisé pour l'autoconsommation et l'aumône de fin de récolte. Ces statistiques sont à l'opposé des cultures pluviales, qui elles, sont destinées à l'alimentation du ménage. 


\section{Les cultures abandonnées}

Le stress pluviométrique des années 60 et 80 qui a affecté l'ensemble du Sahel n'a pas épargné le département de Kantché dans son ensemble (Madiodio, 2007 ; Hulme et al., 2001 ; GIEC, 2001). La canne à sucre, la patate douce, le manioc (qui est devenu secondaire), le concombre sont abandonnés depuis la péjoration des conditions pluviométriques en raison de leur exigence en eau et leur cycle de production relativement élevé. Aucun des paysans du site ne cultive la canne à sucre malgré le gain que cette culture génère.

\section{Les contraintes de production}

Les conditions pluviométriques aléatoires, la baisse de la fertilité des sols due à l'usage excessif des pesticides, les attaques parasitaires et les techniques culturales sont les principaux freins à l'émergence des cultures maraichères dans la zone.

\section{Les conditions pluviométriques aléatoires}

Comme annoncé, les cultures irriguées constituent un moyen d'amélioration des revenus paysans qui souffrent d'un manque de perspectives économiques et de revenus stables. La majorité de la population vit principalement de l'agriculture pluviale et vivrière. Cependant, même les cultures irriguées sur le site sont liées à la pluviométrie. La problématique de production se résume en termes de la baisse progressive de la production engendrée par les difficultés de captage de la nappe phréatique qui sont ellesmêmes liées au phénomène de ruissellement. Ainsi, l'irrégularité et l'insuffisance des précipitations peuvent avoir un impact négatif sur les quantités produites, à cause del'abaissementde la nappe. Il faut des puits plus profonds pour atteindre la nappe phréatique (8 mètres à plus pendant la période sèche).

\section{L'usage des pesticides et la baisse de la fertilité}

Plusieurs problèmes rendent difficiles les pratiques sur le site. L'une des préoccupations majeures reste la question de la fertilité du sol. Elle est mise à rude épreuve à cause de la surexploitation, des moyens d'exhaure pour la plupart traditionnels, du faible accès aux produits phytosanitaires, du crucial problème d'utilisation anarchique des pesticides faute d'encadrement technique (photo1 et 2). 


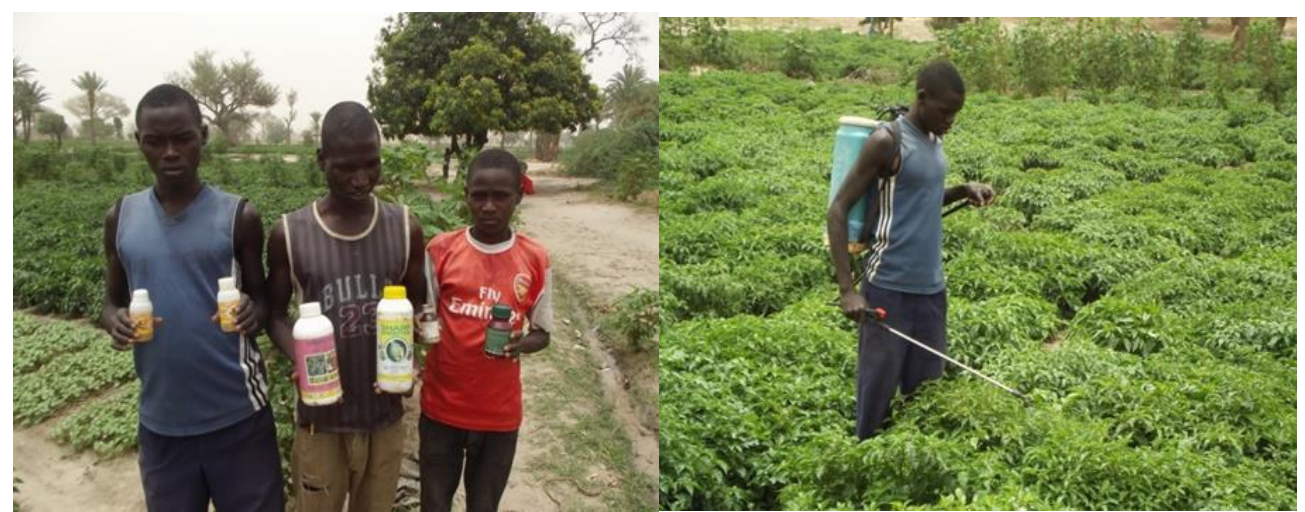

Photo 1 : Exemple de pesticides utilisés Photo 2: Arrosage des plantes par les pesticides Source : Enquête de terrain, 2016

Les pesticides utilisés échappent aux contrôles des techniciens de l'agriculture du département de Kantché. Ils sont fabriqués localement ou alors achetés au Nigéria voisin en dehors de toute homologation. Les conséquences sont également liées au risque de contamination de la nappe phréatique qui sert aussi de boisson pour les paysans (photo3).

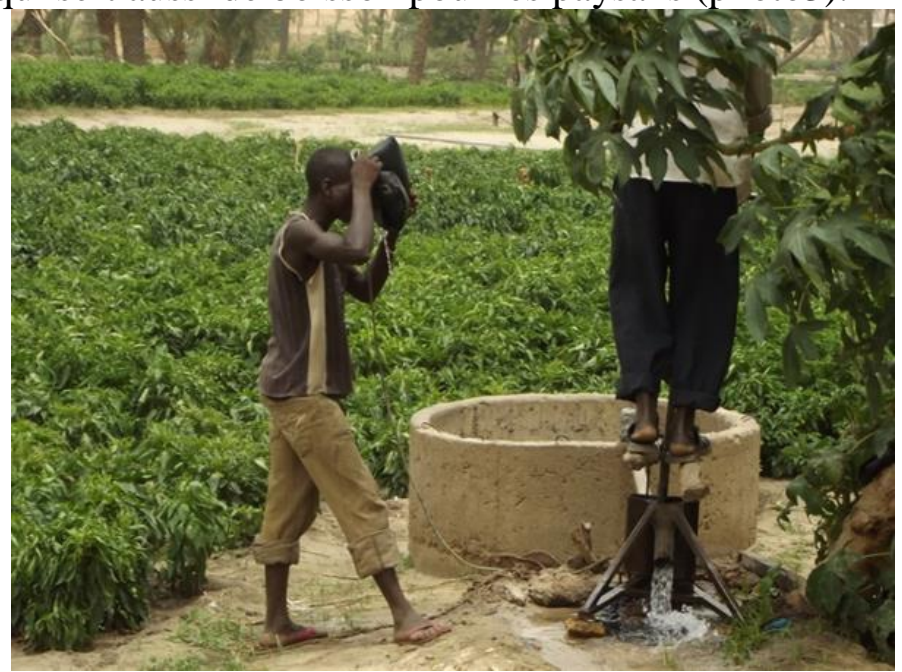

Photo 3 : Utilisation de l'eau de la nappe comme boisson Source : Enquête de terrain, 2016

Comme l'indique la photo 3, les conséquences de l'usage anarchique des pesticides, peuvent aussi avoir des impacts sur la santé humaine. Des analyses chimiques sont nécessaires pour évaluer et confirmer les risques.

\section{Les attaques parasitaires}

Les attaques parasitaires sont fréquentes sur le périmètre. Elles sont un frein au cycle végétatif normal des plantes et réduisentles récoltes. Pour lutter 
contre ces attaques, les paysans font appel au seul technicien de l'agriculture de la commune de Kantché. La figure 7 montre les types d'insectes nuisibles aux plantes.

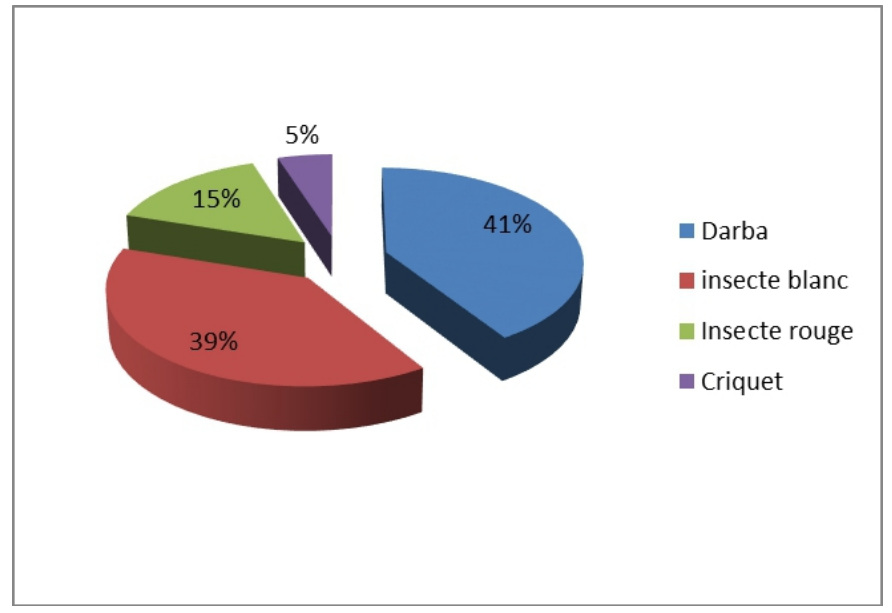

Insecte blanc $=$ Pémisia $;$ Insecte rouge $=$ Aphiscracivora

Figure 7 : Fréquence des insectes nuisibles aux plantes. Source : enquête terrain 2016

\section{Les techniques culturales}

Les techniques de production sur le site restent encore traditionnelles. Les paysans manquent de moyens modernes capables d'impulser des rendements meilleurs. Les principaux outils de production sont la daba, l'arrosoir qui tend de plus en plus à être remplacé par le système des canaux sur le site pour arroser les jardins. La hache, la pelle, les râteaux, la houe, le coupe-coupe. Ils sont utilisés pour labourer le périmètre. Suite à l'abaissementde plus en plus profond de la nappe phréatique, les exploitants utilisent des pommes à motricité humaine et des motopompes pour faciliter l'arrosage. En dépit de cela, les exploitants expriment leurs satisfactions visà-vis de leurs moyens de travail. Ce qui démontre le problème de prise de conscience que les producteurs doivent avoir pour rentabiliser davantage leur activité.

\section{Discussion}

Le maraichage dans le département de Kantché est, à la lumière des résultats, une activité qui se pratiquent avec plusieurs contraintes. Les principales sont ici liées aux disparités dans l'accès au foncier, à l'évolution des cultures, aux conséquences des changements climatiques et des contraintes de production en rapport avec la pluviométrie, les techniques culturales traditionnelles, l'utilisation anarchique des pesticides et les attaques parasitaires. Ces résultats rejoignent ceux de l'étude socioéconomique conduite par Berton et $a l$, en 2008 sur la sécurité alimentaire des ménages de Kantché notamment dans les aspects fonciers et de Siégnounou 2011qui a 
mené ses études au Nord du Burkina Faso à Ouahigouya. Cette étude a permis de catégoriser les populations : les très pauvres, les pauvres, les moyens et les plus nantis. Les très pauvres et les pauvres représentent $67 \%$ des ménages, les moyens $19 \%$ et les nantis $14 \%$. Les surfaces cultivées sont très faibles chez les moins aisés (0,8ha), ce qui ne leur permet pas en bonne année de nourrir leur famille. HEA SAHEL2016, démontreque les activités agricoles font face à des menaces qui limitent leur apport sur le bien-être de la population, dans le département de Kantché. Ces menaces sontla prolifération des ennemis de cultures (parasites, oiseaux et sautereaux, criquet, etc.), l'insuffisance (mauvaise répartition) de la pluviométrie (poche de sécheresse, une installation tardive des pluies et une mauvaise répartition des pluies dans l'espace et dans le temps), la dégradation des sols, l'insuffisance d'encadrement technique des producteurs, l'accessibilité à la terre, le manque de structure de crédits aux producteurs. Dans le Plan de Développement de la Commune de Kantché (PDC, 2014), les contraintes de la commune dans le domaine agricole sont les suivants :

- la faible production ;

- la dégradation de terres de culture ;

- l'insuffisance des matériels agricoles modernes ;

- l'insuffisance de terres de culture ;

- l'érosion éolienne et hydrique ;

- l'insuffisance d'intrants agricoles (semences et engrais) ;

- le déficit pluviométrique ;

- l'insuffisance des produits phytosanitaires.

Les études réalisées sur l'identification des contraintes des cultures irriguées sont unanimes sur les différents problèmes que connait la zone(CTA and FARA 2011; Griffon et al. 2001). Les difficultés peuvent être classées en contraintes physiques et environnementales. Il faut tout de même noter que certaines études soulignent comme contraintes majeures au développement des cultures irriguées, les aspects socioéconomiques. C'est le cas de la SDR (Stratégie de Développement Rural)qui souligne que l'insuffisance des revenus en milieu rural est l'une des causes majeures de la baisse des rendements car de façon générale, au Niger, les capacités d'investissements des paysans sont liées à leur pouvoir économique.

\section{Conclusion}

La pratique du maraîchage dans le département de Kantché est au regard de ces résultats confrontée à plusieurs contraintes. Sur le plan foncier, il existe de grandes disparités entre producteurs dans la répartition des superficies cultivables. 3\% possèdent le plus grand nombre de parcelles. L'héritage reste encore le principal canal de transmission de la terre, mais 
l'achat prend de plus en plus de l'ampleur en raison de la monétarisation des rapports en milieu rural.

Par ailleurs, l'étude ressort que le choix des cultures est fonction du contexte socioéconomique et environnemental. Les changements et variabilités climatiques ont fait abandonner aux populations la culture de certaines denrées comme la canne à sucre, trop gourmande en eau. Par contre de nouvelles variétés sont exploités (poivron, piment vert, carottes, etc.). Ce changement exprime l'adaptation dont fait preuve cette communauté pour faire face aux changements du climat et de l'environnement économique. L'autre aspect des contraintes est lié à la baisse de fertilité des sols, aux attaques parasitaires, aux pratiques culturales peurespectueusesde l'environnement et bien sûr les conditions pluviométriques défavorables.

Il est évident que s'il faut œuvrer dans la promotion de l'économie rurale à travers les cultures irriguées, il faut nécessairement examiner la question de l'eau et de filière. C'est pourquoi, cette problématique s'impose: quelles sont les contraintes liées à la gestion de l'eau et de filière sur les périmètres irrigués de Kantché ?

\section{References:}

1. Apollin, F. (2016). Rapport d'activités : Agronomes et vétérinaires sans frontières, $\mathrm{p} 17$

2. Benoit, G. (2016). Eau, agriculture et changement climatique: statuquo ou anticipation, rapport $\mathrm{n}^{\circ} 16072$, p 66

3. Berton, H, Dodo, M.A,(2008). Enquête rapide sur la sécurité alimentaire des ménages du département de Kantché, Région de Zinder-Avril 2008, Save the children, p28

4. CTA, FARA, . (2011). Contributions Des Finalistes de l'édition 20092010 Des Concours Scientifiques Ouverts Aux Femmes Africaines et Aux Jeunes Professionnels. Innovations Agricoles Au Service Du Développement Durable 3(2):208.

5. GIEC,.(2001). Bilan 2007 des changements climatiques: conséquences, adaptation et vulnérabilité. Résumé à l'intention des décideurs. Contribution du groupe de travail II au troisième rapport du GIEC. OMM.PNUE, $81 \mathrm{p}$

6. Griffon, Michel et al. (2001). Filières Agroalimentaires En Afrique: Comment Rendre Le Marché plus Efficace.

7. Hulme, M.(2001). Climatic perspectives on Sahel iandesiccation: 1973-1998. Global Environmental Change, pp. 19-29.

8. Illou, M. (2007). Le développement local : enjeux et stratégies des différents acteurs (2007). Mémoire de DEA de géographie, Département de Géographie, Faculté des Lettres et Sciences Humaines, Université Abdou Moumouni de Niamey 
9. Kassibo,B. (2002). Priorités nationales et intérêt local. Des grands barrages à la décentralisation. In: Orange D, Arfi R, Kuper M, Morand $\mathrm{P}$, Poncet $\mathrm{Y}$, eds. Gestion intégrée des ressources naturelles en zones inondables tropicales. Paris : Éditions IRD : 119-130p.

10. Leyronas, S. (2016). Notes techniques/technical reports : gestion des ressources en eau souterraines comme biens communs, p 236

11. Madiodio, (2007). Eléments de la stratégie régionale d'adaptation aux changements climatiques basés sur l'approche de partage des risques. Rapport final du Programme ACCA. P 52

12. Mahé, G.(2002). Crue, inondation et production halieutique. Un modèle prédictif des capture dans le delta intérieur du Niger. In : Orange D, Arfi R, Kuper M, Morand P, Poncet Y, eds. Gestion intégrée des ressources naturelles en zones inondables tropicales. Paris : Éditions IRD. pp 865-884.

13. MHE/LCD,.(2005). Consultant sectorielle sur l'environnement et la lutte contre la désertification: document 1: cadre stratégique et opérationnel. Septembre 2005,P 58 p.

14. Ministère des Ressources animales,. (2003). Stratégie de développement rural, République du Niger, $76 \mathrm{p}$

15. Orange, D.(2000). Influence des aménagements hydrauliques et hydro-agricoles du Niger supérieur sur l'onde de la crue du delta intérieur du Niger au Mali. Sud Sciences et Technologies, pp. 16-31.

16. Siégnounou, B. (2011). Impacts Des Changements Climatiques Sur Les Cultures Maraîchères Au Nord Du Burkina Faso: Cas de Ouahigouya. Ouagadougou, Burkina Faso: RENAE.

17. Yamba, B.(1993). Ressources ligneuses et problèmes d'aménagement forestier dans la zone agricole $d u$ Niger, Thèse de doctorat, Tome I, Université Michel Montaigne Bordeaux, 286 p.

18. Yamba, B. (2002). Etude des facteurs et perceptions sociales de la vulnérabilité, Rapport SMALL TAG, 4 p.

19. Yamba, B. (2004). Les mutations des systèmes agraires et les modes d'usage des ressources naturelles dans la zone centrale du Niger, in Revue de géo alpine vol. 92

20. Yamba, B. (2016). Echelle et impact de régénération naturelle au Niger. Rapport final, Ministère de l'environnement et $d u$ développement durable, Direction des Eaux et Forêts, République du Niger, 74 p.

21. Yamba, B.(2017). Echelle et impact de régénération naturelle au Niger. Rapport final, Ministère de l'environnement et $d u$ développement durable, Direction des Eaux et Forêts, République du Niger. 74 p. 